MLM- -3401

DE87 004040

\title{
High Strength Glass-Ceramic to Metal Seals
}

\author{
Lowell D. Haws, Daniel P. Kramer, \\ William E. Moddeman, and George W. Wooten
}

\section{Issued: December 1, 1986}

\author{
DISCLAIMER
}

This report was prepared as an account of work sponsored by an agency of the United States Government. Neither the United States Government nor any agency thereof, nor any of their employees, makes any warranty, express or implied, or assumes any legal liability or responsibility for the accuracy, completeness, or usefulness of any information, apparatus, product, or process disclosed, or represents that its use would not infringe privately owned rights. Reference herein to any specific commercial product, process, or service by trade name, trademark, manufacturer, or otherwise does not necessarily constitute or imply its endorsement, recommendation, or favoring by the United States Government or any agency thereof. The views and opinions of authors expressed herein do not necessarily state or reflect those of the United States Government or any agency thereof.

\section{MOUND}

Miamisburg, Ohio 45342

operated by

\section{MONSANTO RESEARCH CORPORATION}

a subsidiary of Monsanto Company

for the

\section{U. S. DEPARTMENT OF ENERGY}




\section{Contents}

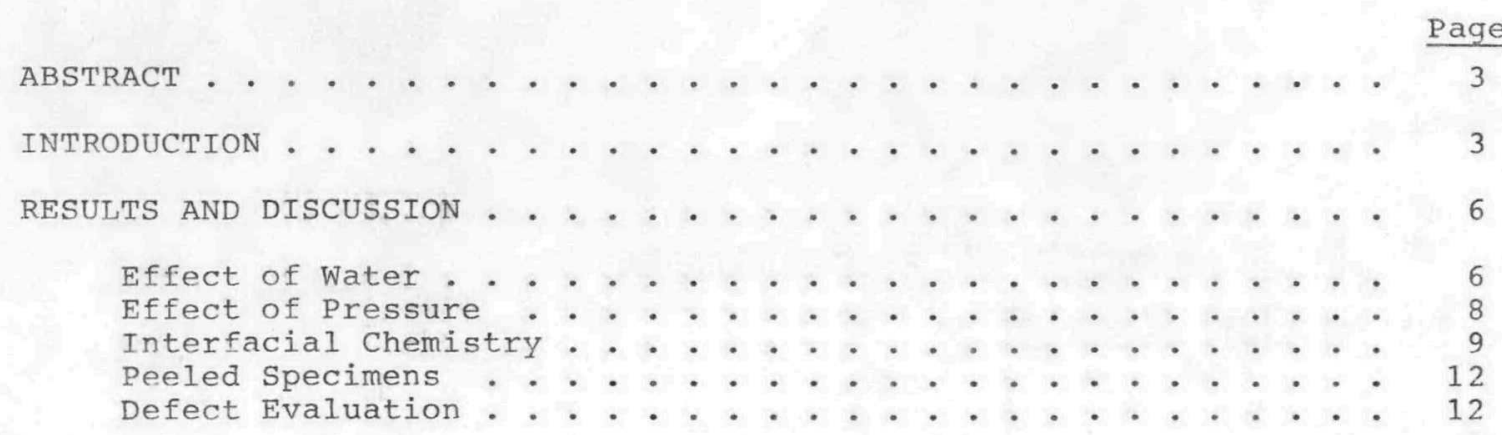

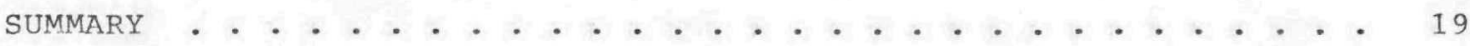

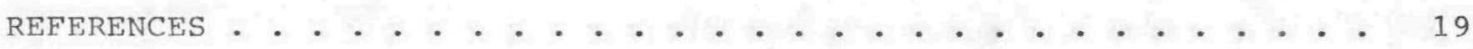

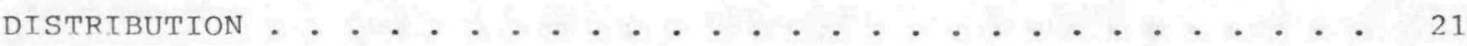




\section{DISCLAIMER}

This report was prepared as an account of work sponsored by an agency of the United States Government. Neither the United States Government nor any agency Thereof, nor any of their employees, makes any warranty, express or implied, or assumes any legal liability or responsibility for the accuracy, completeness, or usefulness of any information, apparatus, product, or process disclosed, or represents that its use would not infringe privately owned rights. Reference herein to any specific commercial product, process, or service by trade name, trademark, manufacturer, or otherwise does not necessarily constitute or imply its endorsement, recommendation, or favoring by the United States Government or any agency thereof. The views and opinions of authors expressed herein do not necessarily state or reflect those of the United States Government or any agency thereof. 


\section{DISCLAIMER}

Portions of this document may be illegible in electronic image products. Images are produced from the best available original document. 


\section{Abstract}

In many applications, ceramics are joined to other materials, especially metals. In such cases, interfacial strength is as important as the strength of each constituent material. Examples are presented for tailoring materials and processes to optimize the glass-ceramic-to-metal seal. Means for detecting defects, nondestructively, are also identified.

\section{Introduction}

Pyrotechnic actuators are small electroexplosive devices that generate high pressure pulses. The gas pressures that are produced can be used to perform a variety of mechanical functions; for example, opening and closing valves. The pyrotechnic material in an actuator is a mixture of a fuel (usually a finely divided metal powder) and an oxidizer. A typical actuator is shown in Figure 1 . In use, the actuator is ignited by a small, resistance-heated wire (W) bridging two or more electrodes (E). These electrodes are electrically isolated and supported by an insulative material (I). A metal sleeve (S) that contains the pyrotechnic powder is also shown.

A reaction can be written for the $\mathrm{Ti} / \mathrm{KClO}_{4}$ pyrotechnic mixture:

$2 \mathrm{Ti}+\mathrm{KClO}_{4}+2 \mathrm{TiO}_{2}+\mathrm{KCl}+$ heat

Based on heats of reaction and on the heat capacities of the reaction products, the final temperature of the gas plume (in particular, gaseous KC1) in the actuator can reach several thousand degrees Celsius. This reaction will cause dynamic pressures in excess of 100,000 psi. In some cases, design intent requires the body of the actuator to maintain structural integrity and total containment of the erosive and corrosive products of the pyrotechnic reaction. Some of the criteria used to select materials to manufacture an actuator meeting these design intents are (1) high temperature oxidation resistance, (2) corrosion resistance to chloride attack, and (3) high strength. In addition, insulator-metal seals must also be hermetic (to $10^{-8} \mathrm{~cm}^{3} / \mathrm{s}$ of $\mathrm{He}$ ), and the stored actuator body must be compatible with the pyrotechnic mixture for 25 yr with no evidence of any chemical degradation of either the body or the pyrotechnic mixture. To ensure compliance, Mound uses high-temperature, corrosion-resistant, nickel-based superalloys as the sleeve (S of Figure 1) and electrode (E) which are sealed with an appropriate glass-ceramic to serve as the insulating (I) support. High strength is ensured by using high-yield-strength materials, by incorporating an appropriate internal design configuration, and by matching coefficients of thermal expansion (CTE) of metals and glass-ceramic. CTE matching is achieved by judicious selection of the time-temperature sealing cycle.

The material set sometimes used is a multicomponent lithia-alumina-silicate glass-ceramic in conjunction with Inconel 718 [1] and Hastelloy C-276 [2] nickelbased superalloys. Compositions of these materials are presented in Table 1 . A glass-ceramic is used rather than a 


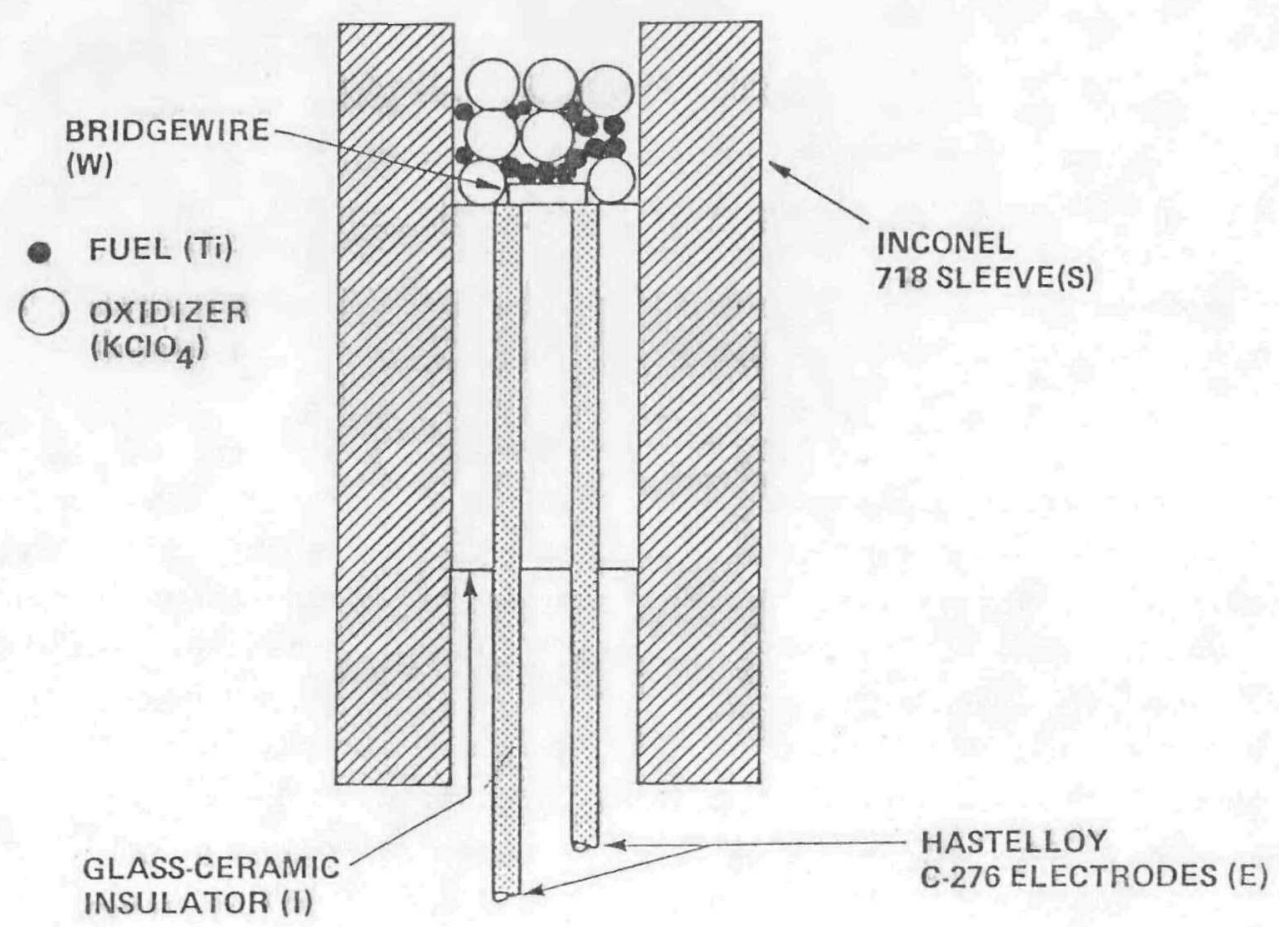

FIGURE 1 - Schematic of glass-ceramic/metal actuator.

Table 1 - COMPOSITIONS OF THE SUPERALLOYS AND GLASS-CERAMIC USED IN FABRICATING ACTUATORS AT MOUND

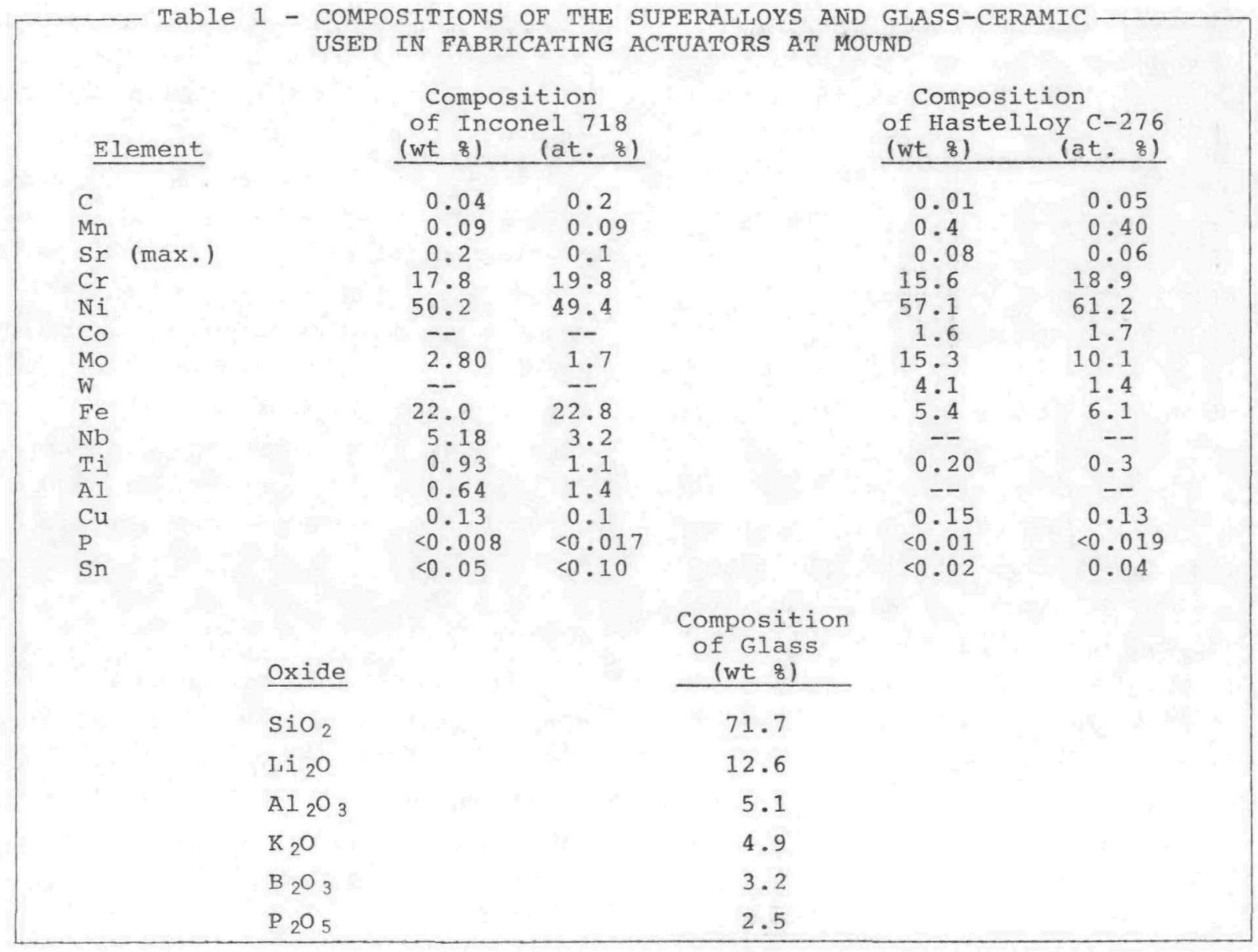


conventional alumina ceramic since the former can be more readily formed into complex geometries using standard glassforming techniques. Transformation of the glass into a high-strength, multiphase glass-ceramic occurs during a carefully controlled high-temperature furnace cycle. Nickel-based superalloys are used because they have high tensile strengths and excellent corrosion resistance.

Processing of glass-ceramic-to-metal seals involves a time-temperature furnace cycle (Figure 2) consisting of three major segments: (1) seal segment - flow of the glass and subsequent formation of a seal with the various metal substrates, (2) nucleation segment - development of crystal nuclei in the glass, and (3) growth segment - formation of crystals on nuclei transforming the glass into a glass-ceramic. The appropriate time and temperature parameters for the different segments depend on the particular material set selected. In general, the temperature during the seal segment must be high enough to reduce the viscosity of the glass sufficiently to permit flow and formation of a seal. The crystal growth temperature can be determined, in general, by performing differential thermal analysis (DTA) on the parent glass. Strength of the ultimate glassceramic-to-metal seal is dependent on, among other factors, matching of the CTE; this matching, in turn, is related to the type and quantity of crystal phases present, which are controlled by timetemperature cycle selection. Predominant phases present in the glass-ceramic for this study along with their CTE are shown in Table 2. The high-thermal-expansion characteristics of the superalloys require that the glass-ceramic also have a high thermal expansion. For optimum compression seals, the CTE for the glass-ceramic should fall between the CTE's for two of the metals. This condition is obtained by controlling the time-temperature furnace cycle to yield a glass-ceramic containing lithium metasilicate, lithium disilicate, and cristobalite.

Processing glass-ceramic-to-metal seals is fairly routine and straight-forward. Good seals can be obtained by controlling the time-temperature furnace cycle and by the careful selection of compatible SEAL NUCLEATE GROWTH

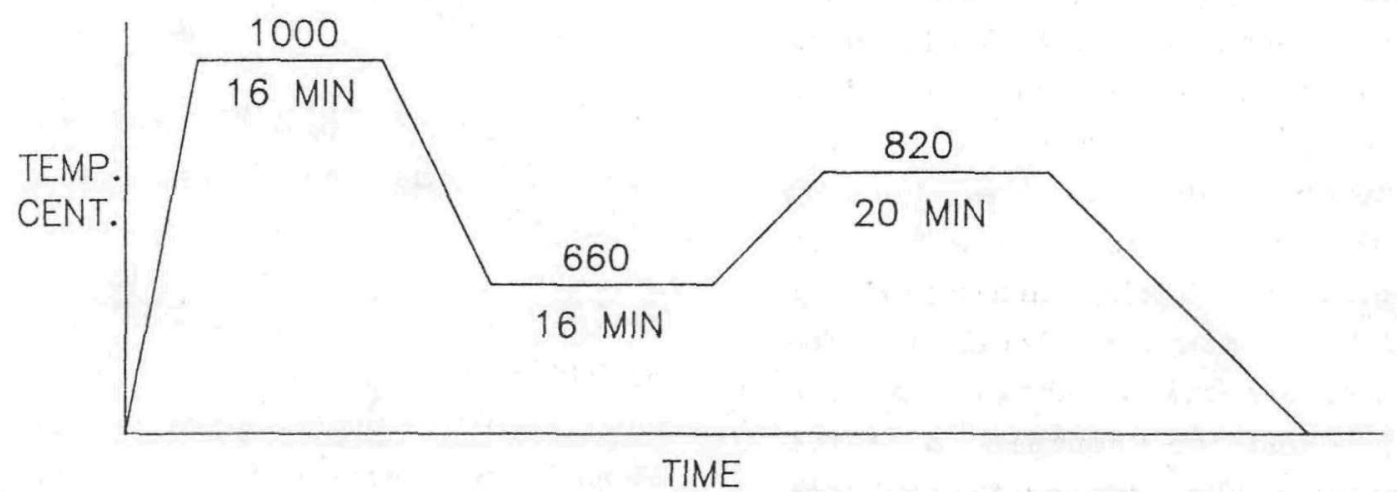

FIGURE 2 - Time-temperature furnace cycle used in processing glass-ceramic-to-metal seals. 
Table 2 - PREDOMINANT PHASES PRESENT IN THE GLASS-CERAMIC AFTER FURNACE CYCLE AND THEIR RESPECTIVE COEFFICIENTS OF THERMAL EXPANSION

Crystal Species
Glass
Lithium Disilicate $\left(\mathrm{Ii}_{2} \mathrm{Si}_{2} \mathrm{O}_{5}\right)$
Lithium Metasilicate $\left(\mathrm{Li}_{2} \mathrm{SiO}_{3}\right)$
Cristobalite $\left(\mathrm{SiO}_{2}\right)$
Quartz $\left(\mathrm{SiO}_{2}\right)$

Coefficient of Thermal Expansion ${ }^{a}$

$90-110 \times 10^{-7}$

$110 \times 10^{-7}$

$130 \times 10^{-7}$

$500 \times 10^{-7}$

$170 \times 10^{-7}$

a Length per unit length per degree Celsius.

Expansion measured from room temperature to $300^{\circ} \mathrm{C}$.

materials. However, the interfacial chemistry of the seal has not been thoroughly investigated and is not well understood. We, at Mound, have been evaluating the effects of subtle changes in selected process parameters on the quality of the interface. Processing parameters that greatly affect the quality of the interface have been determined to be (1) water content (dissolved water in the glass and water in the furnace atmosphere) and furnace gas pressure. These effects are discussed in the following sections.

\section{Results and Discussion}

\section{Effect of Water}

The influence of water on the final properties of a seal is demonstrated by the next two examples. In both situations glass-ceramic-to-metal seals were processed in closed-batch furnaces. In order to reduce the oxidation of the metal substrates during the heating cycle, argon was used as an inert cover gas. An example of the necessity for water control is shown in Figure 3. The component cross-section shown in the figure was found to contain a large bubble, rendering the component unacceptable. Investigation showed that the size

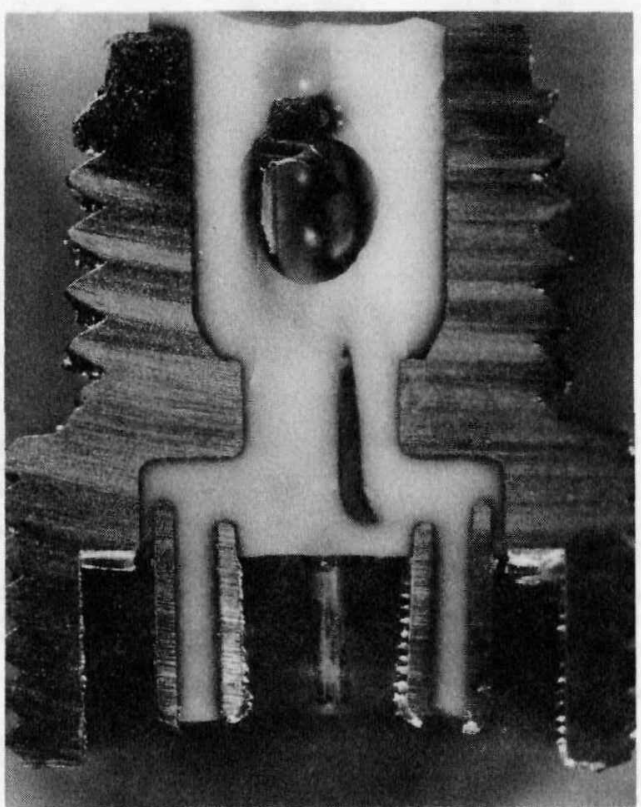

FIGURE 3 - Cross-section of glassceramic/metal component after furnace cycle exhibiting large bubble.

of the bubble formed was a function of time at the seal temperature. Gas chromatographic analysis revealed the presence of hydrogen within the bubble. Initially, the source of hydrogen was puzzling because the furnace cover gas was argon. Thermodynamic calculations showed that hydrogen formation could be the result of water reduction by several 
metallic species. The glass was determined to contain "dissolved water" in quantities sufficient to react with the metallic species at the seal temperature according to the following equation:

$$
\mathrm{xM}+\mathrm{H}_{2} \mathrm{O} \stackrel{1273^{\circ} \mathrm{K}}{\longrightarrow} \mathrm{M}_{\mathrm{x}} \mathrm{O}+\mathrm{H}_{2}
$$

That this reaction indeed occurs was suggested by surface analysis ( $x$-ray photoelectron spectroscopy) where it was shown that chromium, nickel, and iron can diffuse from the metal surface into the glass. Bubbling dry nitrogen through the glass melt significantly reduced the water concentration in the glass [3] and therefore has mitigated bubble formation as shown in Figure 4.

During the development phase of a pyrotechnic actuator, a determination was made that control of the water content of

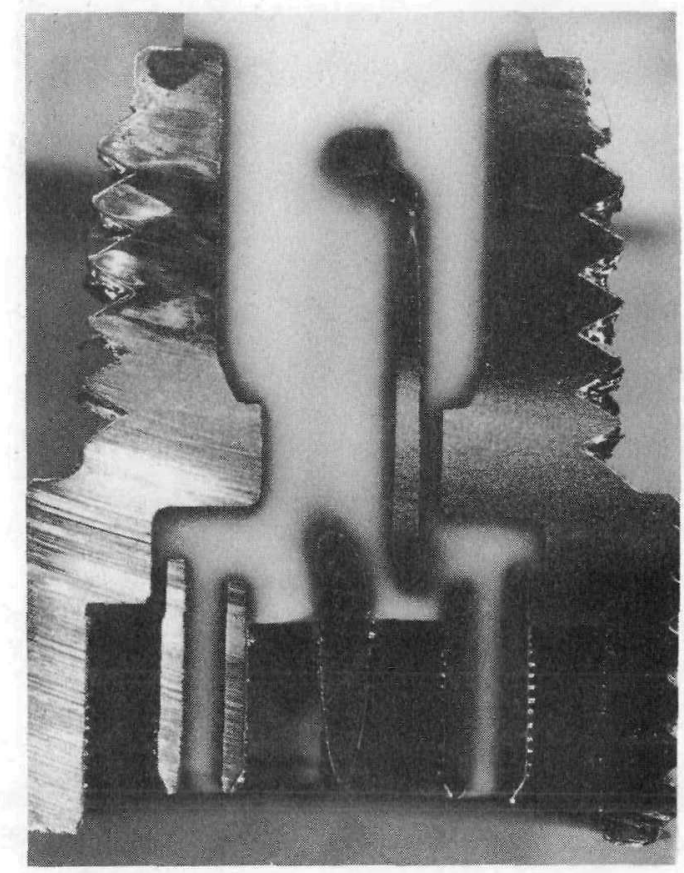

FIGURE 4 - Cross-section of glassceramic/metal component fabricated with "dry" glass showing no large bubble formation. the cover gas is also critical in obtaining good reaction interfaces between glass-ceramic and metal surfaces. Figure 5 shows an optical photomicrograph of a seal interface where the metal has been etched away revealing the glassceramic reaction surface. The seal was formed while under an argon cover gas which had a dew point of $+25^{\circ} \mathrm{C}$. Figure 6 shows the same type of seal that was formed using identical processing parameters but with an argon cover gas which had a dew point of $-40^{\circ} \mathrm{C}$. It is evident that the part shown in Figure 6 has less interfacial porosity, with all of its inherent strength characteristics, than does the part shown in Figure 5 . The only processing difference was the amount of water in the cover gases. Thus, lowering the dew-point of the cover gas significantly reduces interfacial porosity by eliminating the type of reaction shown in Equation 2 .

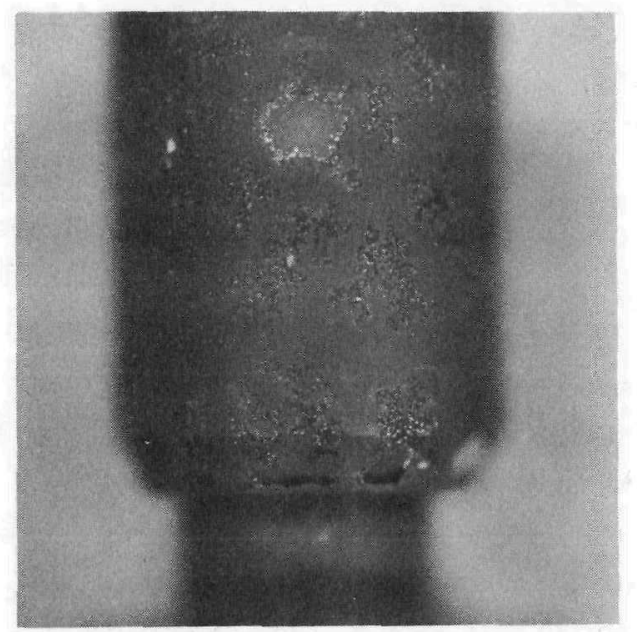

FIGURE 5 - Photomicrograph of glassceramic after metal sleeve has been etched away revealing interfacial porosity, argon cover gas dew point $+25^{\circ} \mathrm{C}$. 


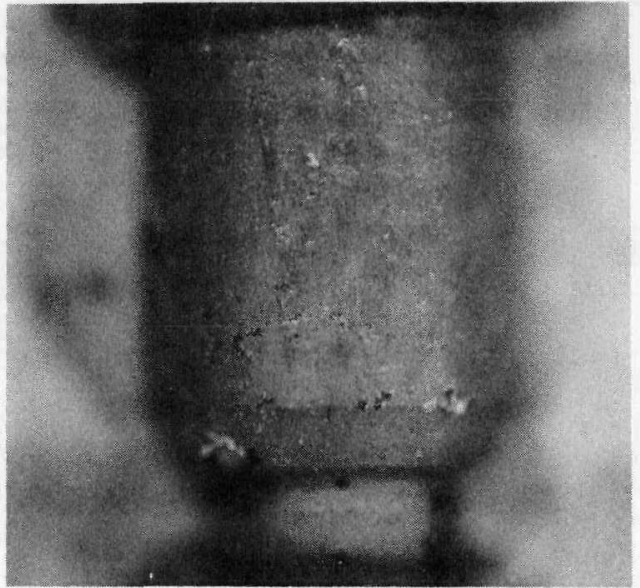

FIGURE 6 - Photomicrograph of glassceramic after metal sleeve has been etched away revealing decreased interfacial porosity, argon cover gas dew point $-40^{\circ} \mathrm{C}$.

\section{Effect of Pressure}

Another technique that has been used to produce high strength glass-ceramic-tometal seals is based on the application of pressure to reduce interfacial porosity. Classical furnace processing of seals is basically two-dimensional, where the principal parameters are time and temperature. However, hot isostatic press (HIP) processing of glass-ceramicto-metal seals is a three-dimensional process: time, temperature, and pressure can be controlled. Some advantages of HIP processing can be observed in Figures 7 and 8 ; these figures show glass-ceramic reaction surfaces exposed by etching away the Inconel 718 sleeves from seals processed in a HIP and in an ambient pressure (classical) furnace, respectively. The most apparent advantage of the HIPprocessed glass-ceramic/Inconel 718 seal is the decrease in porosity at the interface. Obviously, this leads to an

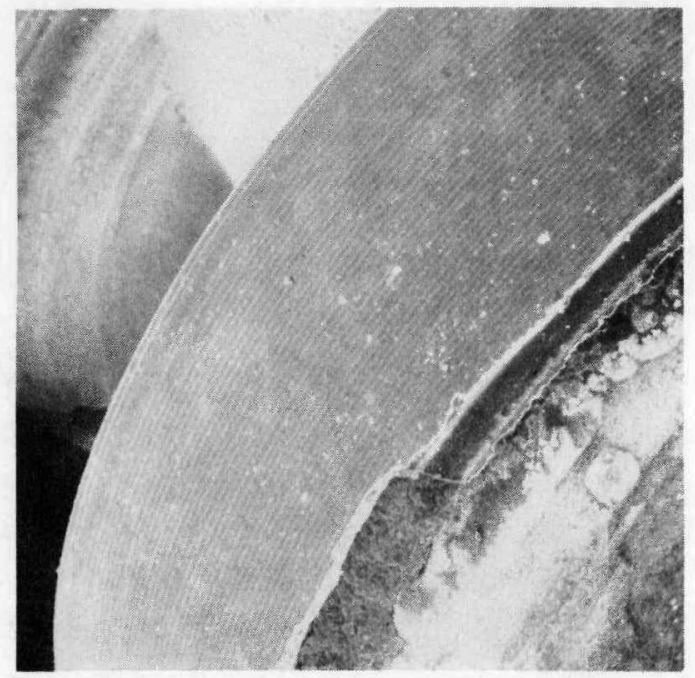

FIGURE 7 - Photomicrograph of glassceramic to metal interface, prepared by HIP processing $(30,000$ psi).

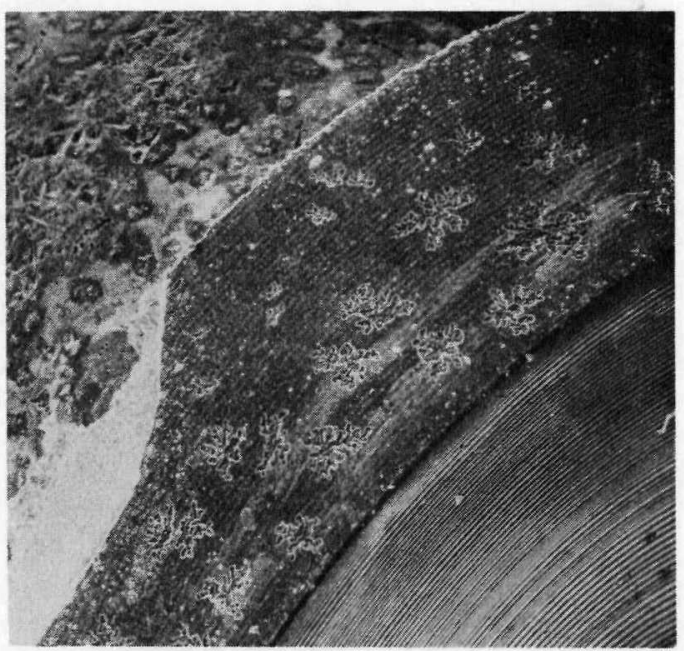

FIGURE 8 - Photomicrograph of glassceramic to metal interface, prepared in a "classical," ambient pressure furnace.

increase in the interfacial strength of a HIP-processed seal.

HIP processing also affects formation of the crystalline phases in the glassceramic. Figure 9 compares the $x$-ray 


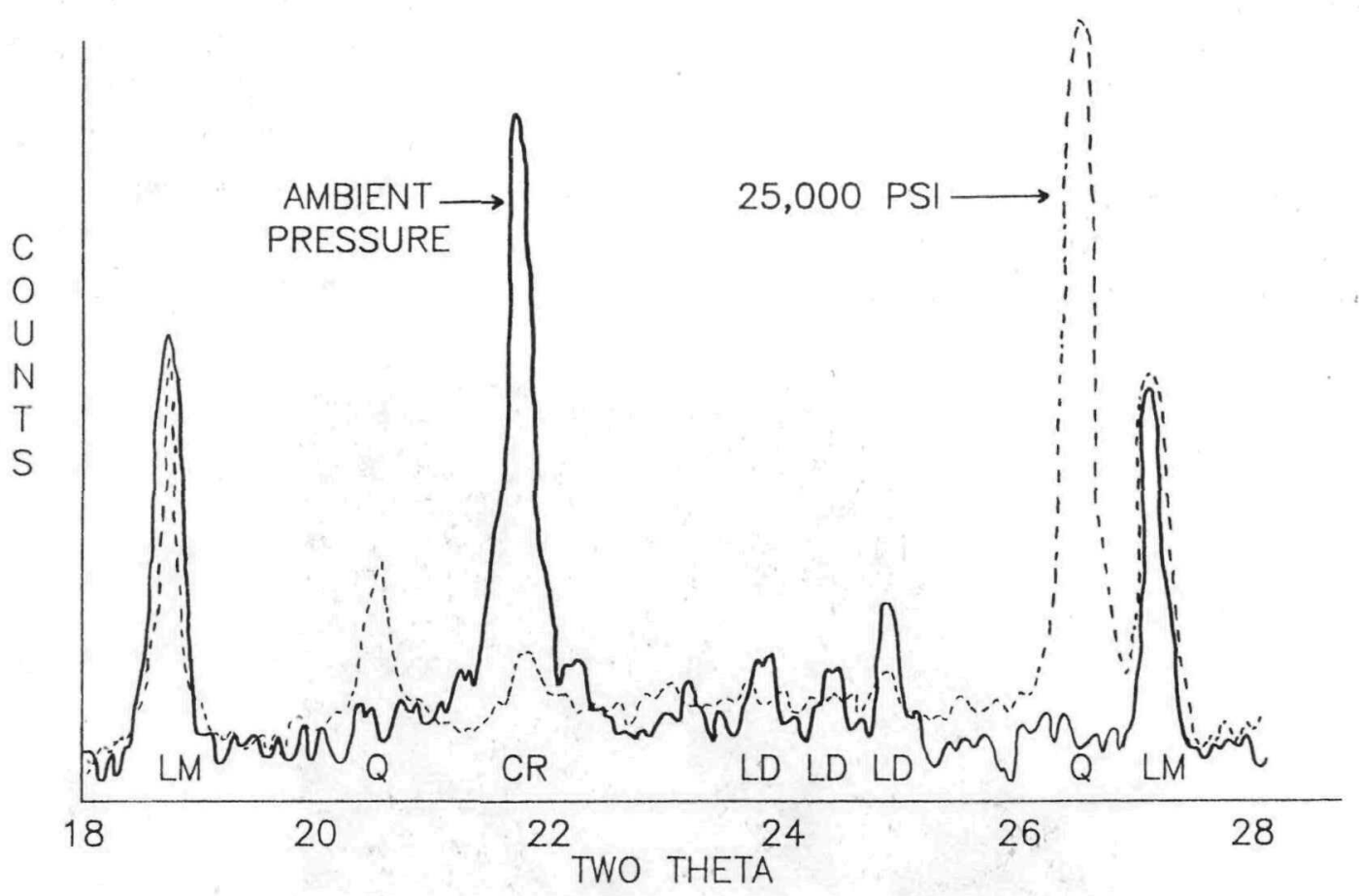

FIGURE 9 - Comparison of x-ray diffraction patterns of the glass-ceramic produced during HIP processing (25,000 psi) and "classical" processing (ambient pressure). The following symbols apply: LM = Lithium Metasilicate, LD = Lithium Disilicate,

$Q=$ Quartz, CR = Cristobalite.

diffraction patterns (between two theta angles of $18^{\circ}$ and $28^{\circ}$ ) for the glassceramic produced in the normal timetemperature cycle (Figure 2) with that for the HIP cycle; the only difference between the two methods was the 25,000 psi applied during the HIP cycle. Crystalline phases produced in the HIP cycle were different from those produced in the normal (nonpressurized) furnace. In HIP sealing, lithium metasilicate and quartz were the predominant phases, whereas lithium metasilicate, lithium disilicate, and cristobalite were the predominant phases produced in the nonpressurized cycle. This phenomenon is in keeping with geological formations, where quartz is the polymorph of silica at higher pressures [4].

\section{Interfacial Chemistry}

Interfacial chemistry subsequently affects hermeticity, strength, and the corrosion resistance of glass-ceramic-tometal seals. We have examined the interfacial chemistry of such seals by studying (1) polished cross-sections and (2) peeled specimens. The analytical techniques used in these studies were wavelength dispersive $\mathrm{x}$-ray (WDX) and $\mathrm{x}$-ray photoelectron spectroscopy (XPS).

To produce an exaggerated condition and facilitate studies of interfacial reactions, seals were made by holding the temperature at $1000^{\circ} \mathrm{C}$ for $66 \mathrm{hr}$ (the normal cycle, as shown in Figure 2, is $1000^{\circ} \mathrm{C}$ for $\left.15 \mathrm{~min}\right)$. The cross-section of a polished glass-ceramic-to-metal seal is 
shown in Figure 10. Particles and voids are readily observed in the interface region.

A WDX line scan across a particle is shown in Figure 11. This particle was approximately $100 \mu \mathrm{m}$ from the interface.
The line scan illustrates the distribution of elements on and off the particle. The particles are primarily phosphides with a stoichiometry of $\mathrm{M}_{2} \mathrm{P}$ where $\mathrm{M}=$ chromium, nickel, noibium, or iron [5]. Away from the seal and into the bulk of the glass-ceramic $(>0.15 \mu \mathrm{m})$, the

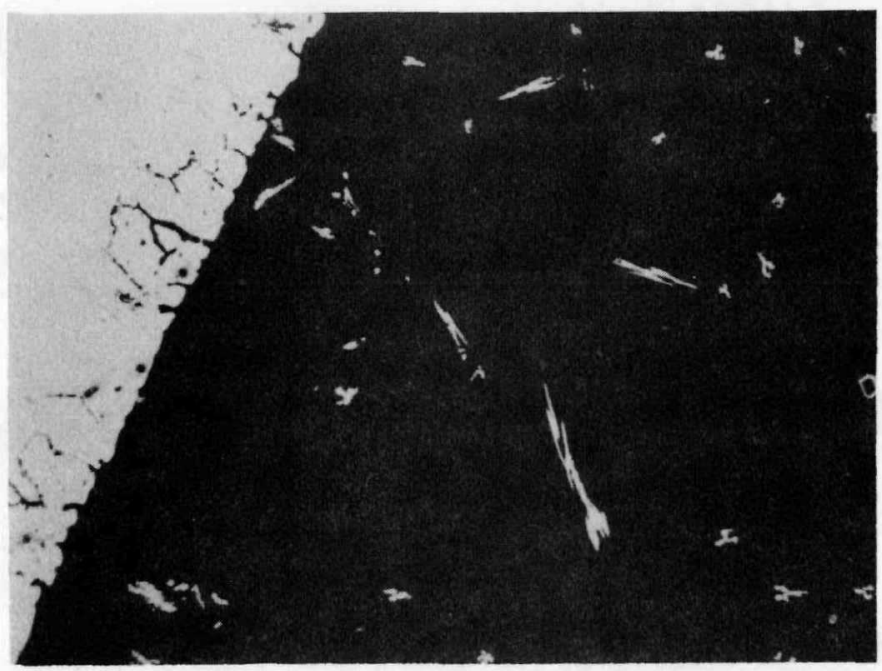

FIGURE 10 - Photomicrograph of glass-ceramic/metal interface sealed at $1000^{\circ} \mathrm{C}$ for sixty-six hours.

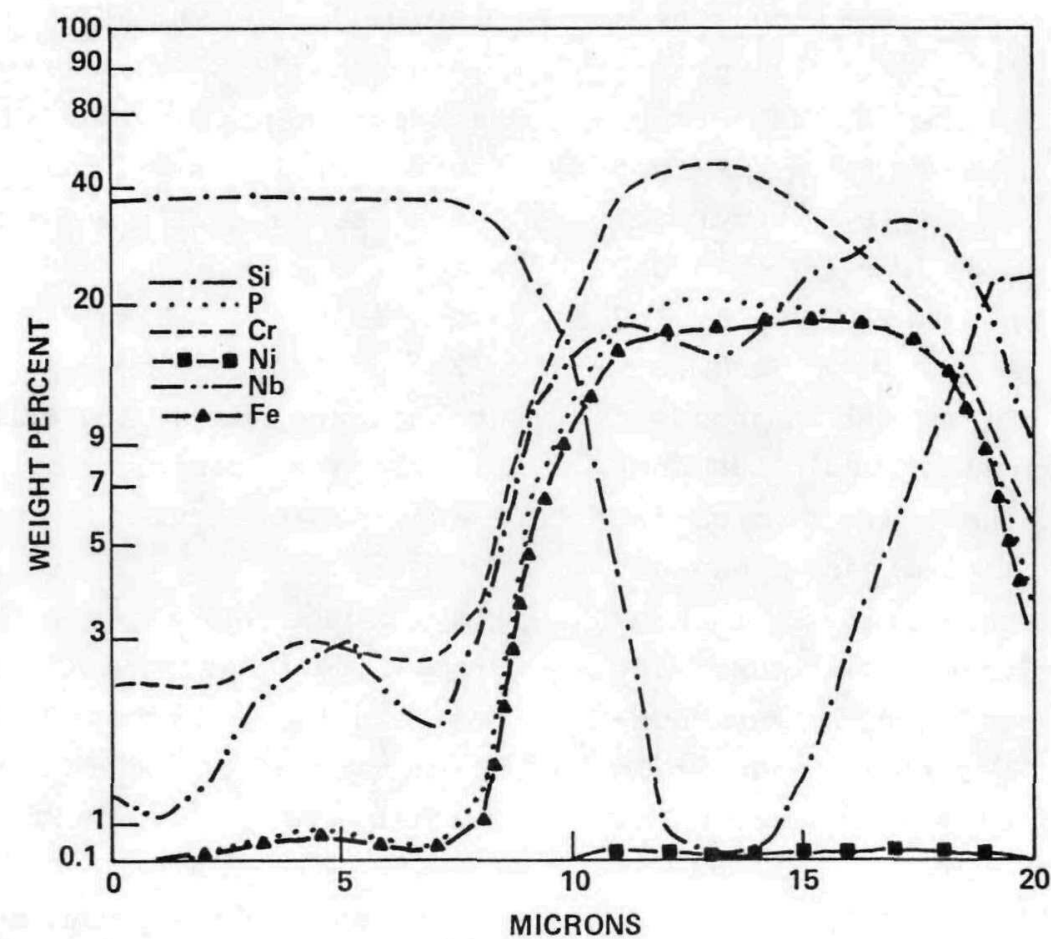

FIGURE 11 - Wavelength dispersive analysis line-scan across an interfacial particle. 
particles are primarily $\mathrm{Cr}_{2} \mathrm{P}$; closer to the interface region the particles are higher in nickel, iron, and niobium concentrations. Off the particles, in the glassy phase, a small concentration of metals, at the few atomic percent level, is observed. The metals observed in the glassy phase (nickel, niobium, titanium, chromium, and iron) are from the Inconel and Hastelloy. The oxidation state of these various elements was determined by XPS [6]. Niobium and titanium were present in the glass in the positive five (+5) and positive four (+4) oxidation states, respectively; on the other hand, nickel was primarily present as zero valent metal. Iron and chromium

(a) Nickel

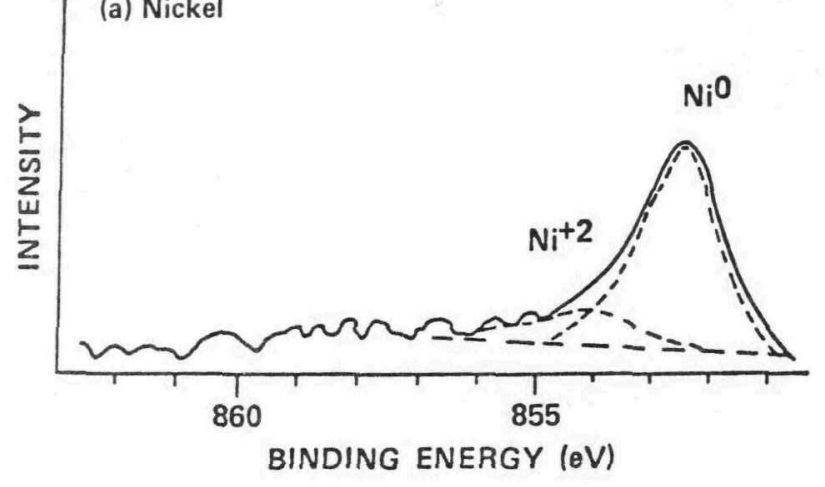

(c) Chromium

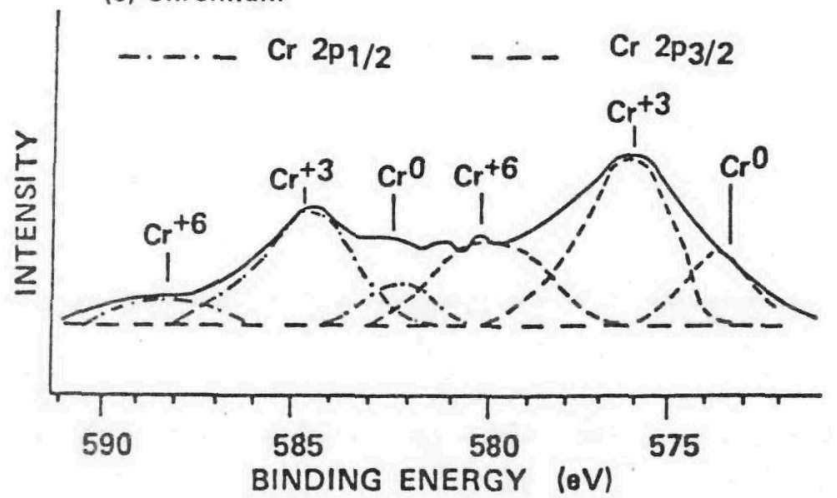

were found present in mixed oxidation states. Figure 12 depicts the XPS scans for nickel, niobium, chromium, and iron.

The WDX and XPS results are explained on the basis of sequential events; namely, (1) dissolution of Inconel into the glassy phase and (2) subsequent reaction of the metals with either the dissolved oxygen or the constituents of the glass; e.g., $\mathrm{P}_{2} \mathrm{O}_{5}$, $\mathrm{SiO}_{2}$. The dissolved metals [M] will oxidize according to the equilibrium:

$$
\mathrm{M}+\mathrm{x}[\mathrm{O}] \text { glass } \underset{\mathrm{MO}}{\longrightarrow}
$$

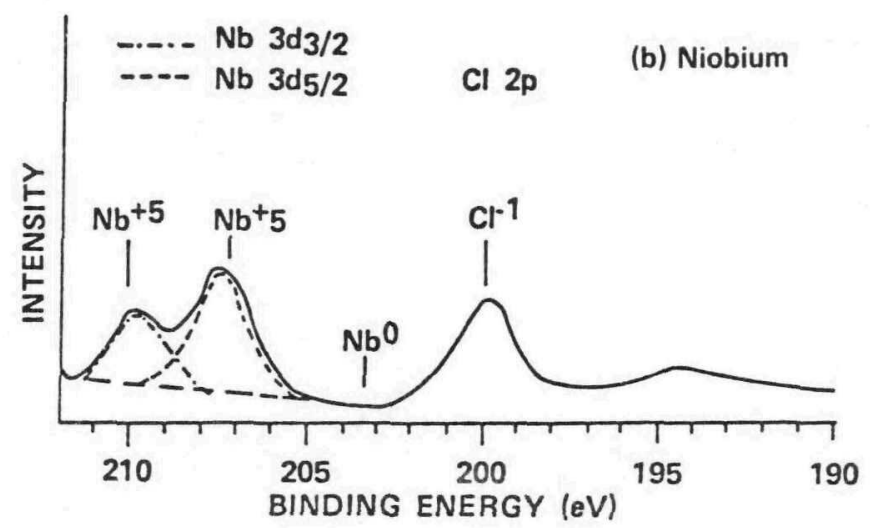

(d) Iron

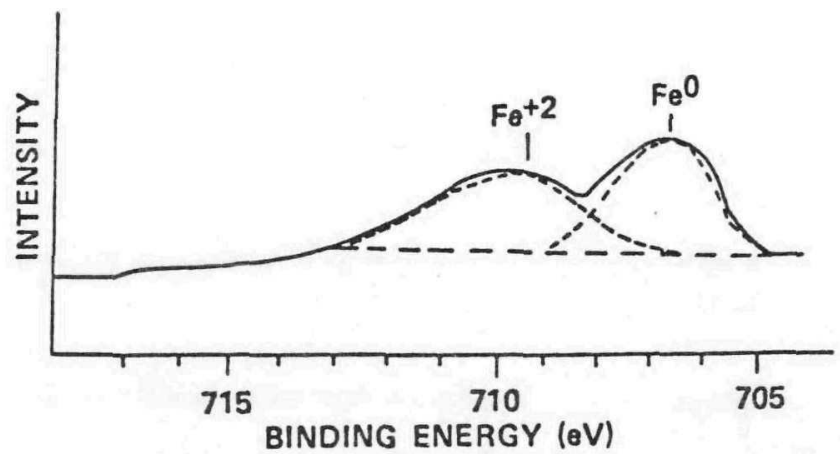

FIGURE 12 - X-ray photoelection spectroscopy of (a) nicke1, (b) niobium, (c) chromium, and (d) iron depicting oxidation states of elements in gTass. 
where the concentration of the oxygen in the glass has been estimated to be $5 \mathrm{x}$ $10^{-16}$ moles per liter [6]. of the metaliic constituents of Inconel, titanium has the greatest affinity to oxidize, and nickel has the least. These metals are also available to react with the components of the glass-ceramic. For example, the formation of metal phosphides can be explained by the reaction:

$$
(2 \mathrm{x}+5 \mathrm{y}) \mathrm{M}+\mathrm{P}_{2} \mathrm{O}_{5} \leftrightarrows 2 \mathrm{M} \mathrm{x}^{\mathrm{P}}+5 \mathrm{M}_{\mathrm{y}} \mathrm{O}
$$

The porosity or void formation at the interface is also noted. This porosity is probably due to the same mechanism for the bubble formation above; that is, Equation 2, where metals, M, mainly involve chromium and titanium.

Thus, from examinations of the interfaces of polished glass-ceramic/metal cross sections, it was shown that metal diffuses from the alloys into molten glass-ceramic where metal is available to react with either the dissolved oxygen in the glass-ceramic or its constituents.

\section{Peeled Specimens}

Another technique to prepare samples for interface evaluation involved peeling the metal from the glass-ceramic. In this technique, an Inconel 718 metal sleeve was machined until it was thin enough to be peeled from the glass. This procedure was performed inside a drybox under flowing argon (<10 ppm water and oxygen). The samples, both metal and glass sides, were transferred directly into the XPS spectrometer without exposure to laboratory atmosphere. The XPS spectra of (a) the metal side and (b) the glass side are shown in Figure 13 (low resolution scans) and Figure 14 (high resolution scans). The spectra for the glass and metal sides are almost mirror images, showing that peeling produces a cohesive failure in the- surface metal oxide on the Inconel 718. In fact, in this region there is less than 1 at. \& silicon, indicating the absence of glass on the metal surface after peeling. Table 3 lists the concentrations detected by these scans.

It is interesting that aluminum appears only in the positive three $(+3)$ state, and nickel only as a zero valent species. Niobium, chromium, iron, and molybdenum are present as a mixture of metal oxides and zero valent species. The mixed chemistry in this peeled area can be explained in terms of the co-existence of an alloy phase, such as $\mathrm{Ni}_{3} \mathrm{Nb}$, with other species such as zero valent metals of nickel, iron, and chromium and can also be explained by the presence of aluminum oxide. This is in agreement with previously reported chemistry observed on the surface of Inconel 718 sealed without the presence of glass [7]. In that XPS study, evidence for $\mathrm{Ni}_{3} \mathrm{Nb}$ alloy was given. From these examinations, it is evident that the peeled interface is complex. Metals, metal oxides, and alloy phases have been identified; some of these can react with water to produce a porous interface which can lower hermeticity and seal strength.

\section{Defect Evaluation}

In an attempt to assess the effect of defects (e.g., bubbles in the bulk glassceramic and interfacial porosityl on performance, a study was begun to evaluate pyrotechnic devices nondestructively prior to destructive performance evaluation. Acoustical measurements are 


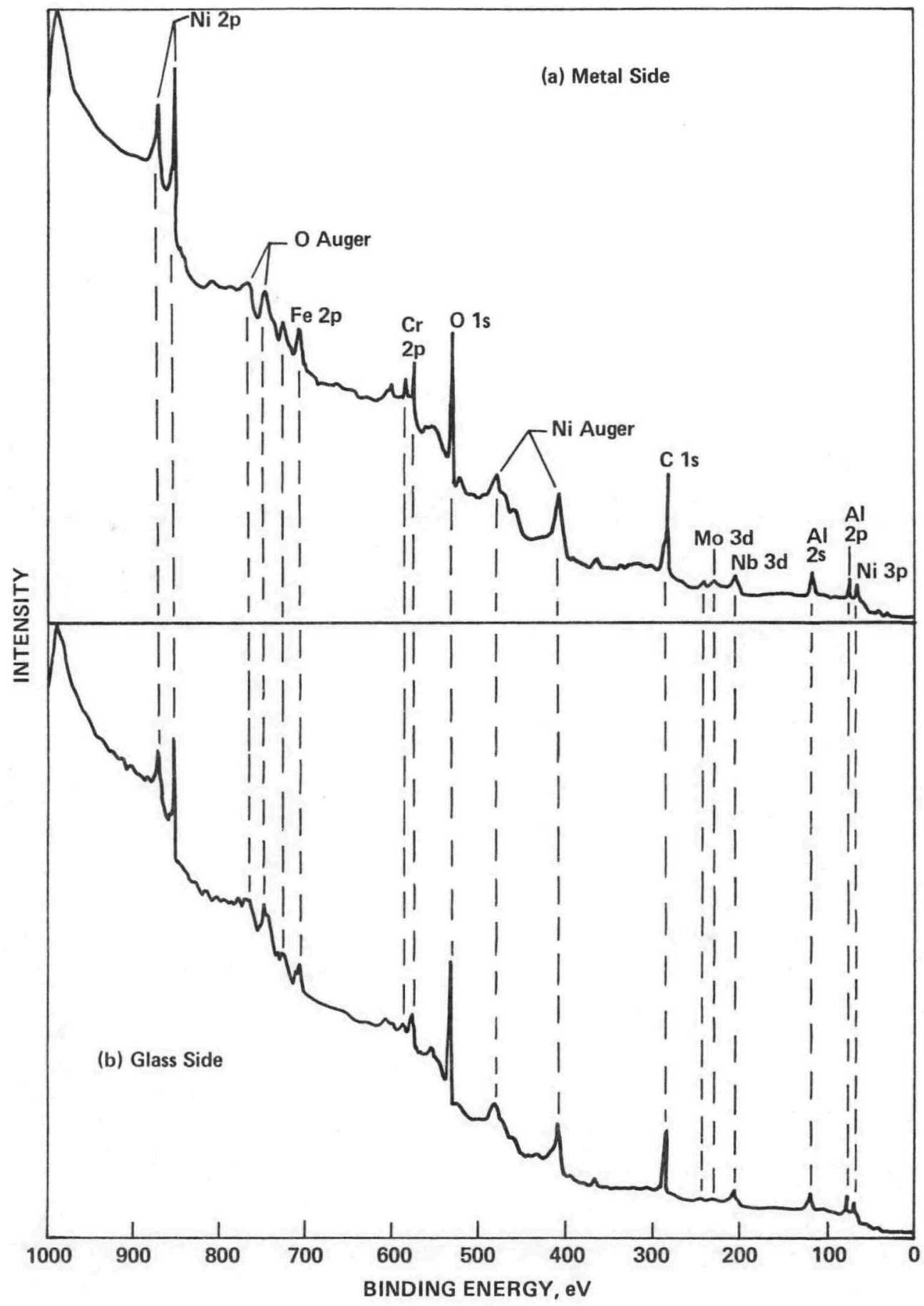

FIGURE 13 - X-ray photoelection spectroscopy low resolution scans of interface exposed by peeling (a) the metal side and (b) the glass side. 

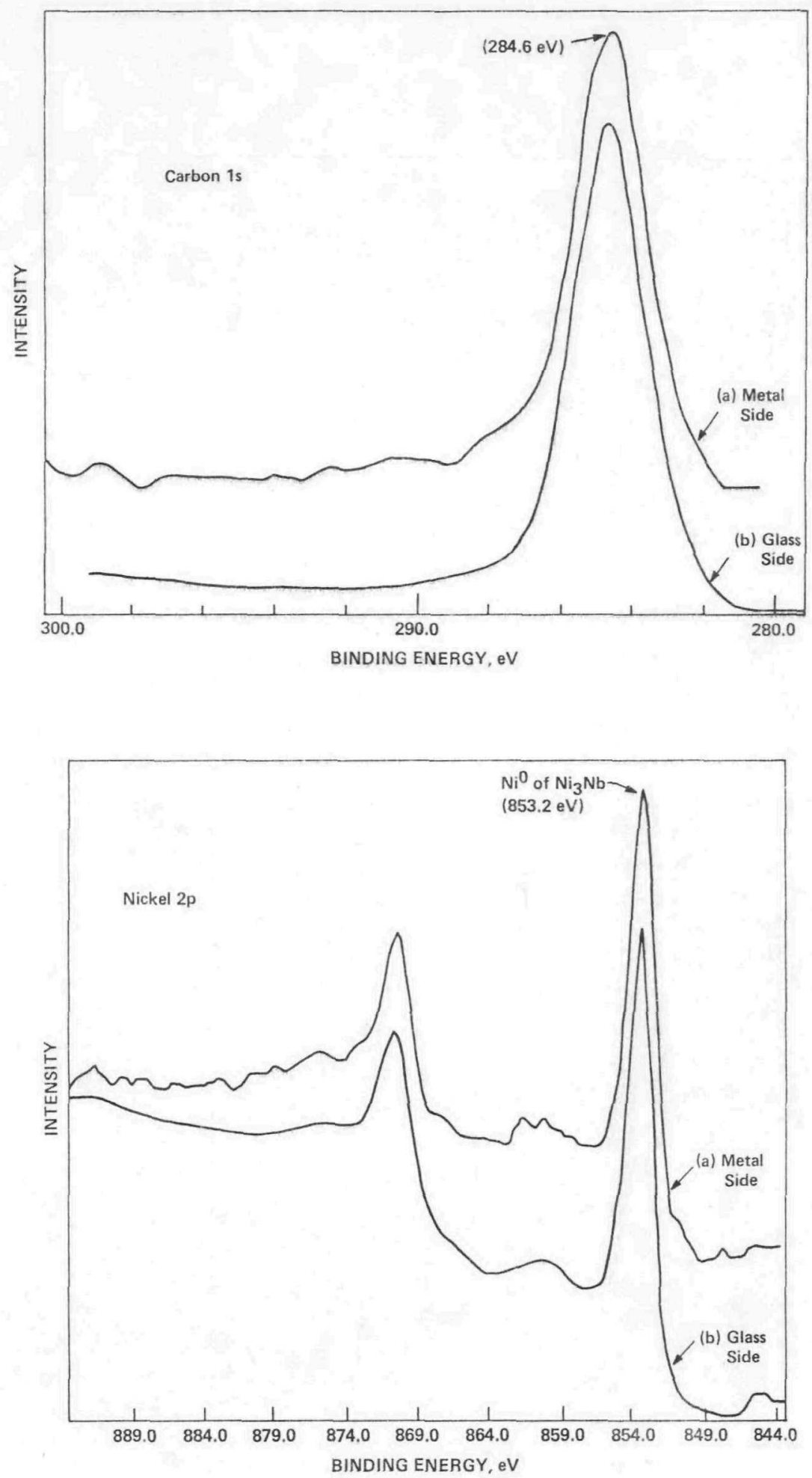

FIGURE 14 - X-ray photoelectron spectroscopy high resolution scans of interface exposed by peeling (a) the metal side and (b) the glass side. 

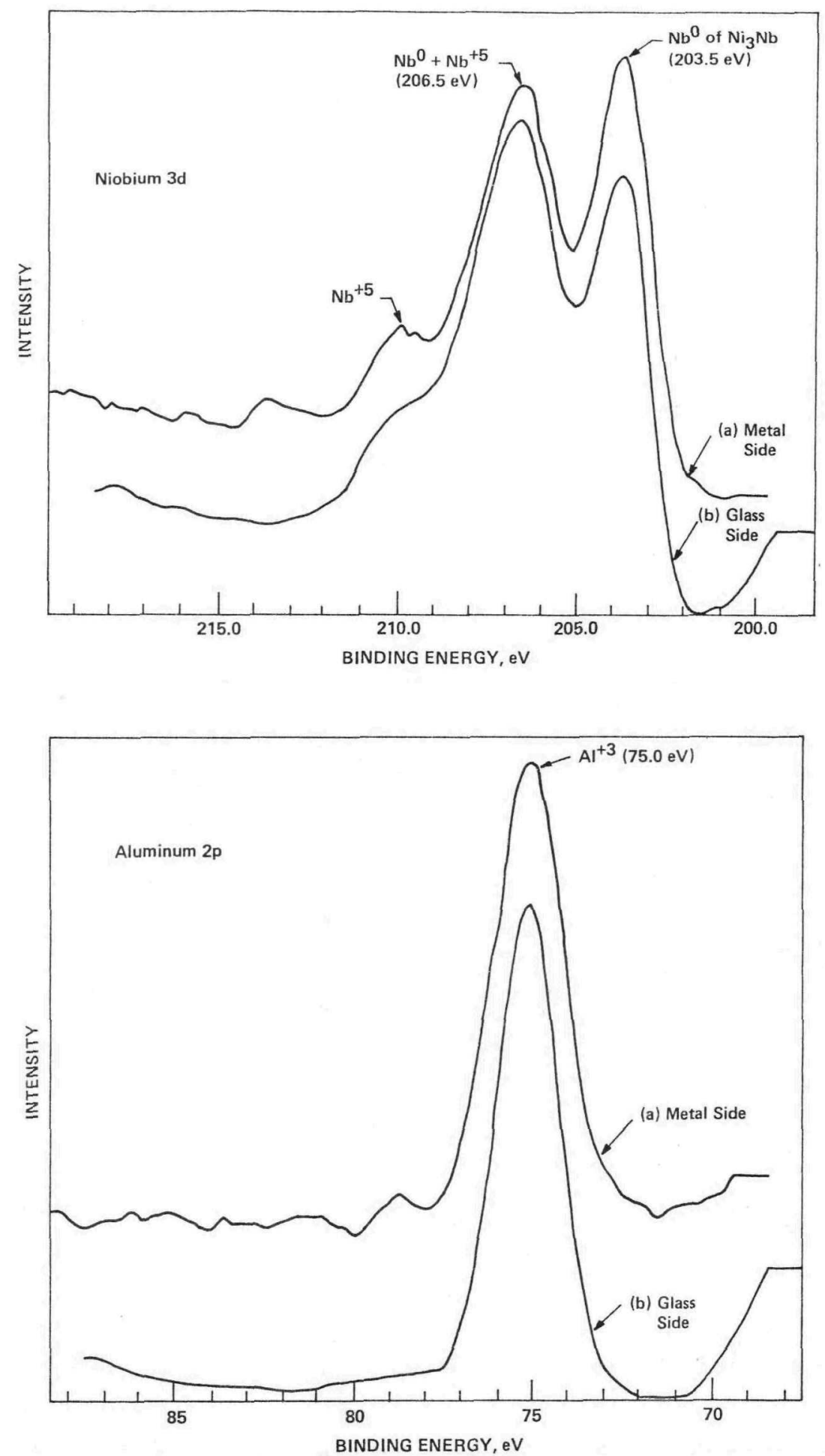

FIGURE 14 - (Continued). 

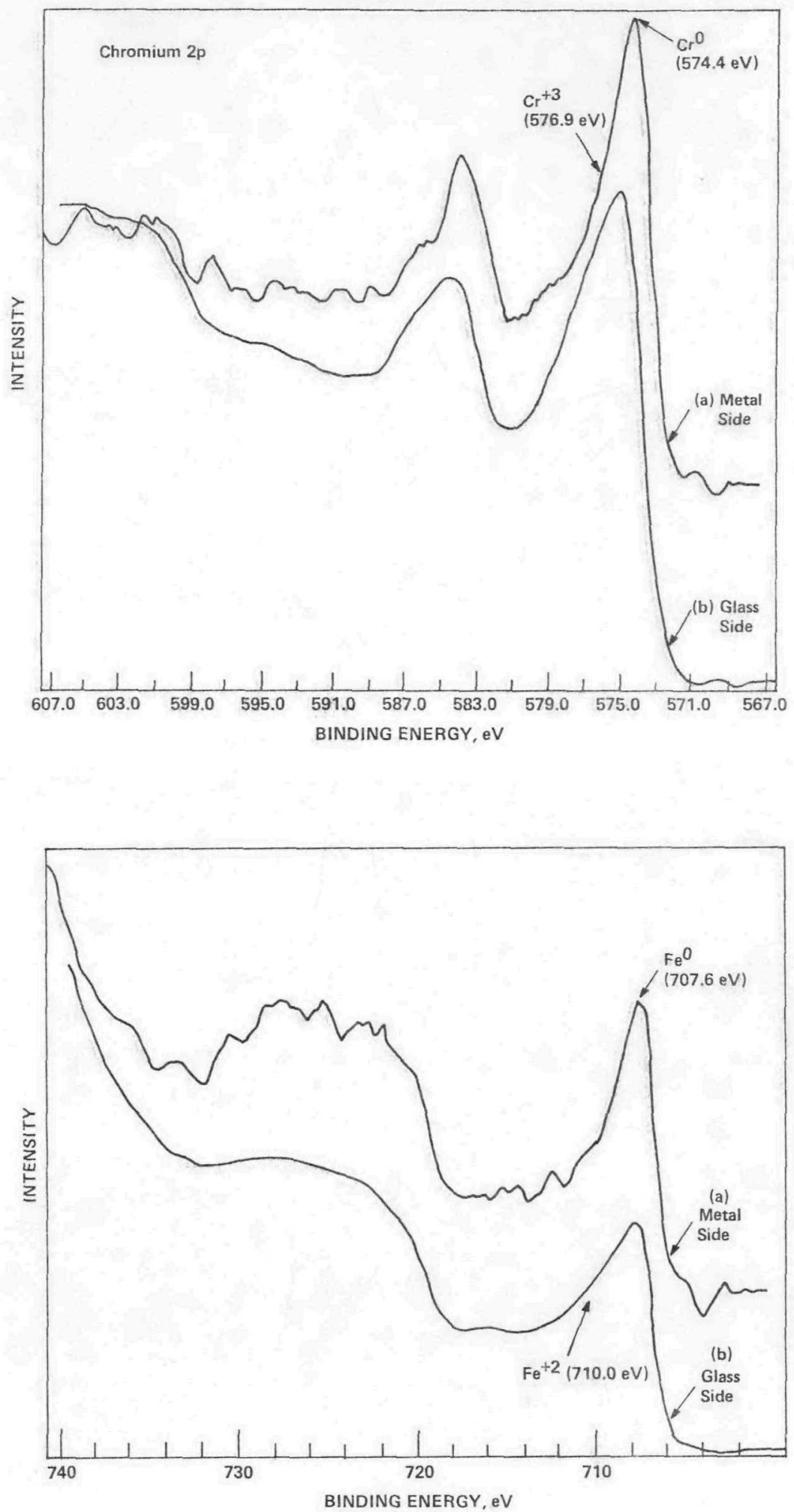

FIGURE 14 - (Continued). 


\begin{tabular}{|c|c|c|c|}
\hline \multicolumn{2}{|c|}{ Metal Side } & \multicolumn{2}{|c|}{ Glass Side } \\
\hline Element & $\begin{array}{c}\text { Concentration } \\
\text { (at. : }) \\
\end{array}$ & Element & $\begin{array}{c}\text { Concentration } \\
\text { (at. of) }\end{array}$ \\
\hline $\mathrm{Ni}$ & 6.45 & $\mathrm{Ni}$ & 4.17 \\
\hline $\mathrm{Fe}$ & 2.83 & $\mathrm{Fe}$ & 1.63 \\
\hline $\mathrm{Cr}$ & 4.33 & $\mathrm{Cr}$ & 2.82 \\
\hline 0 & 22.01 & 0 & 23.67 \\
\hline C & 50.53 & C & 55.64 \\
\hline $\mathrm{Nb}$ & 1.28 & $\mathrm{Nb}$ & 1.28 \\
\hline Mo & 0.22 & Mo & 0.24 \\
\hline $\mathrm{AI}$ & 12.34 & AI & 10.55 \\
\hline
\end{tabular}

nondestructive and generally can be made while the material under study is either at rest or subjected to a variety of external stresses or environments. Of several acoustical techniques considered, acoustic pulse-echo imaging techniques seemed particularly attractive for performing early nondestructive examinations of glass-ceramic structures.

High frequency acoustic pulse-echo imaging is provided by an ultrasonic scanning system that fills the resolution gap between conventional C-scan systems and ultrasonic microscopes. A single, sharply focussed, high-frequency transducer mechanically scans the sample and transmits an acoustic pulse that is propagated through the material under test. Discontinuities in the material reflect the pulse back to the transducer for processing to provide data relative to defect size and location. The system also incorporates a "gate" function that permits depth selection in the test material under examination.

The acoustic pulse-echo imaging approach has been employed successfully to locate and size critical bubbles and boundary defects in glass-ceramic structures incorporated in pyrotechnic actuators. Nondestructive evaluations were made at the completion of the glass-sealing cycle. Sample preparation involved only the removal of excess glass-ceramic by surface grinding. Precise location and sizing of defects approaching one mil in diameter were achieved. Echo images of four different specimens are shown in Figure 15 to illustrate examples of defects and boundary interface conditions. Image A of Figure 15 represents a defect-free condition as indicated by the sharp, uninterrupted view of the device ledge. In contrast, Image $B$ shows the presence of multiple voids, in addition to a porous glass-ceramic/metal interface. After being scanned, the metal was removed by acid etching to confirm actual defect and boundary layer conditions. Three bubbles were found in the glassceramic at the ledge interface along with an extremely porous boundary layer. The photograph of the device with the shell etched away shows both the void and boundary condition. Images $C$ and $D$ further illustrate the potential of 

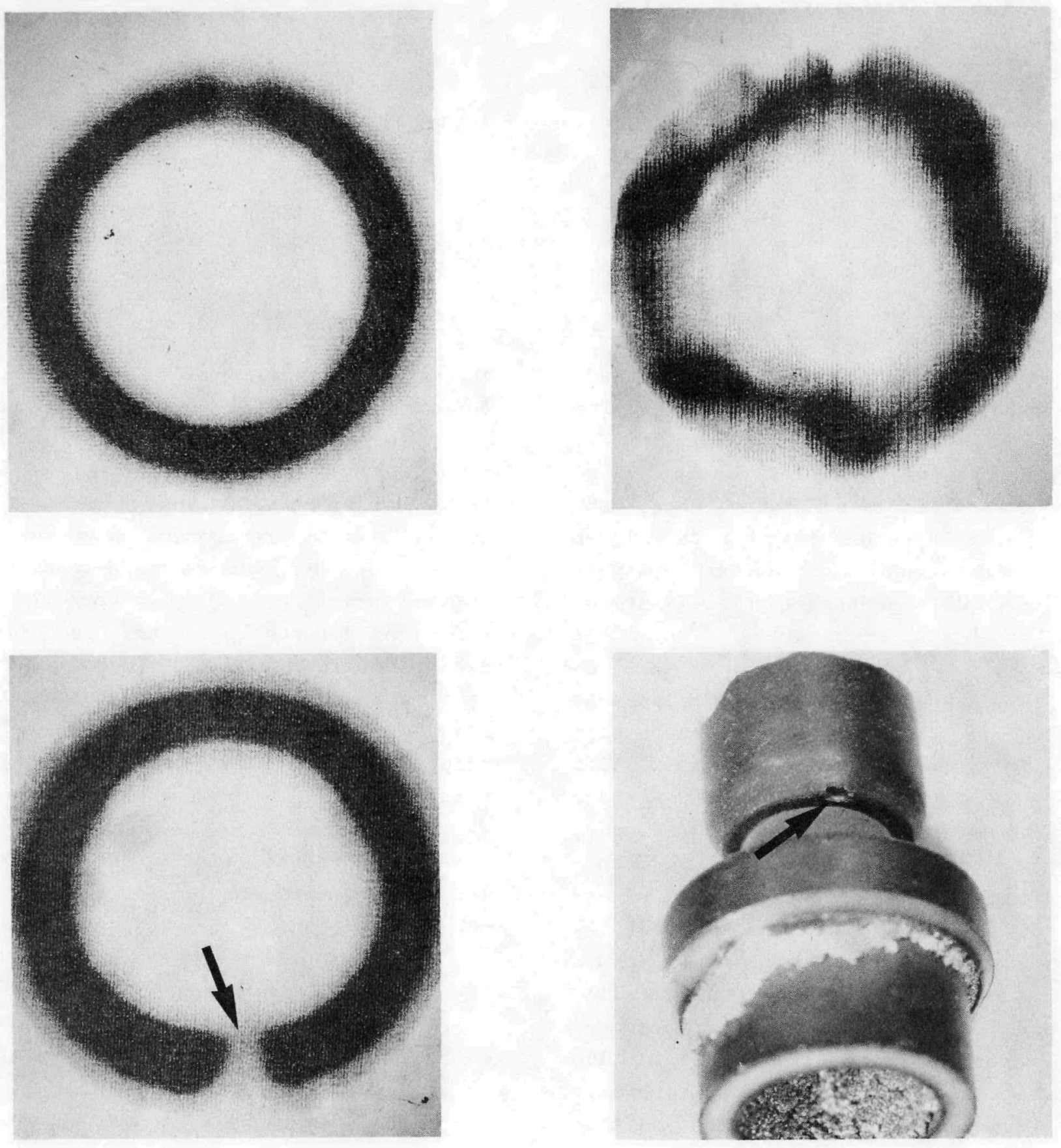

FIGURE 15 - Photo acoustic pulse-echo image of interface region illustrating defect structure. 


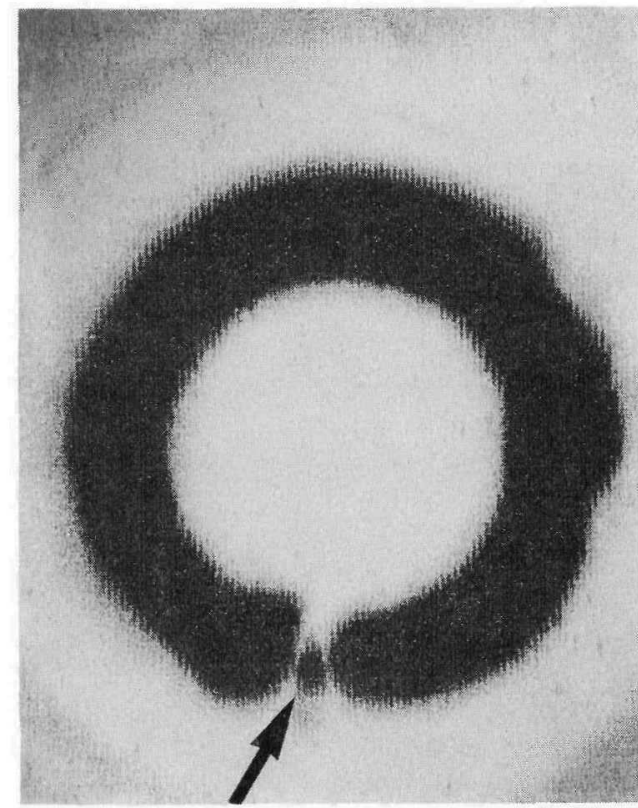

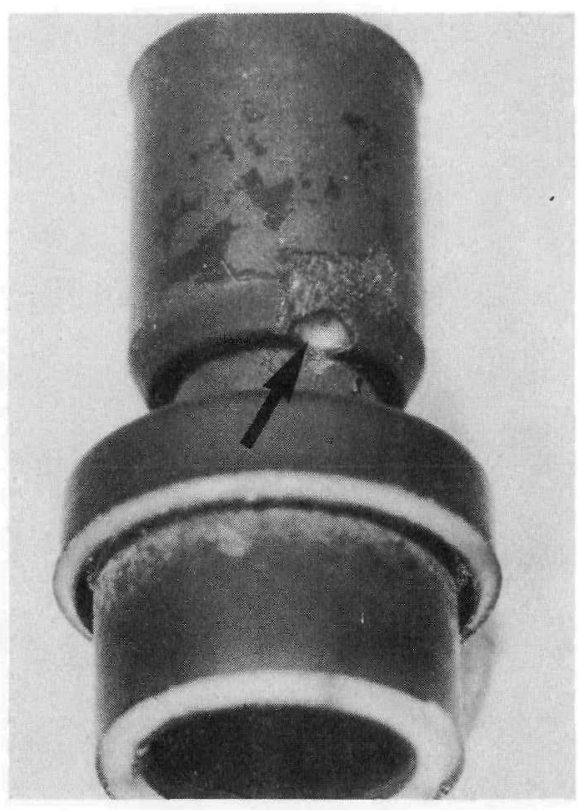

FIGURE 15 - (Continued).

acoustic pulse-echo imaging in detecting and characterizing bulk defects and boundary conditions nondestructively. Image $C$ shows good boundary conditions and a single void at the ledge interface. This is validated by the corresponding photographs of the glass-ceramic body remaining after removal of the metal sleeve by acid etching. Both void and boundary layer conditions are evident. opposite conditions are illustrated by Image D. Here, a single void as well as grainy areas in the boundary layer are illustrated.

\section{Summary}

In the past several years our understanding of the nature of glass-ceramic-tometal seals was advanced as a result of cause and effect studies such as those cited in this report. We have found that the material set selected for a specific application influences the process conditions used if a high strength seal is required. Both material set and process conditions affect the chemistry and the defect structure at the interface. With the advent of high-frequency acoustic pulse-echo imaging, we are in a position to evaluate interfacial defects nondestructively and, therefore, to perform definitive fault studies.

\section{References}

1. Inconel 718, Huntington Alloys, Inc., Huntington, West Virginia.

2. Hastelloy C-276, Cabot Corporation, Kokomo, Indiana.

3. Nease, A. B., M. D. Hale, and D. P. Kramer, Water Analysis of GlassCeramic by FT-IR spectroscopy, MLM-3127 (1983), 21 pp.

4. Mason, B., and L. G. Berry, Elements of Mineralogy, W. H. Freeman and Company, San Francisco, 1968, pp. 406-409. 
5. Moddeman, W. E., S. M. Craven, and

7. Kramer, D. P., S. M. Craven, D. P. Kramer, "Ni${ }_{3} \mathrm{Nb}$ Alloy in Oxide Surfaces of Inconel 718," Metall. Trans. A, 17A, 351-356 (1986), MLM-3338 (J) .

6. Moddeman, W. E., S. M. Craven, and D. P. Kramer, "Evidence for Diffusion of Zerovalent Metal Atoms R. E. Schneider, W. E. Moddeman, and D. W. Brohard, Chemistry of GlassCeramic to Metal Bonding for Header Application 1. Effect of Treatment on Inconel 718 and Hastelloy $\mathrm{C}-276$ Metal Surfaces, MLM-3132 (1984), $37 \mathrm{pp}$. Ceram. Soc./Commun. Am. Ceram. Soc., 68:11, $C-298-C-300$ (1985), MLM-3284 (J) . 


\section{Distribution}

\section{External}

TIC, UC-25 (177)

G. R. Gartrel1, DAO/DOE

J. A. Morley, DAO/DOE

H. A. Schneiderman, Monsanto, St. Louis

Monsanto Reports Library, St. Louis

General Electric Neutron Devices Division

R. H. Briston

Los Alamos National Laboratory
F. D. Gac
W. H. Meyers
O. A. Lee
W. W. Whaley
R. McCormick

Sandia National Laboratories, Livermore

R. $\mathrm{Ng}$

A. J. West
Lawrence Livermore National Laboratory
H. A. Golopol
R. L. Landingham
C. L. Hoenig
N. A. Schneider, Jr.

Sandia National Laboratories, Albuquerque
L. C. Allen
R. E. Loehman
D. H. Anderson
N. J. Magnani
O. L. Burchett
D. H. Doughty
H. J. Saxton
R. J. Eagan
F. J. Villa
F. P. Gerstle, Jr.
R. D. Watkins
J. G. Harlan
P. R. Wengert
D. B. Hayes
P. D. Wilcox

H. L. McCollister

\section{Internal}

J. D. Braun

J. R. Brinkman

D. A. Buckner

H. S. Carden

D. I. Coffey

R. J. Desando

E. E. Egleston

C. L. Fellers

L. D. Haws (2)

W. B. Hogeman

C. W. Huntington
D. P. Kelly

F. D. Lonadier

W. E. Moddeman

G. I. Numbers

W. D. Pardieck

W. H. Smith

R. E. Vallee

H. A. Woltermann

G. W. Wooten (2)

Publications

Library (15)

Marjorie F. Hauenstein, Editor

Technical Communications 